\title{
An anti-Covid vaccine
}

The announcement of successful-i.e. reaching the final stage of clinical trials - vaccines and their subsequent approval by national regulatory agencies (Table 1) has elicited great excitement among the general public and governments alike. Furthermore, dozens of anti-Covid vaccines are still in development around the world, and it is reasonable to suppose that some of these, too, will be successful and gain approval. In terms of the SIR model [1], vaccination transforms "susceptible" (S) into "recovered" (R) without passing through the intermediate "infectious" (I) state. It thus accelerates the attainment of population immunity [2]. Furthermore, it appears that for those who contract the disease despite having been vaccinated, it diminishes the severity of symptoms and mortality. This is particularly important for the custodians of national health services, because it decreases the need for hospitalization and, hence, the burden on the service, the containment of which was a major stimulus for the strict lockdown policies that have been enacted in many countries. The corollary is that as soon as the degree of vaccination among the population warrants it (depending on the number of $\mathrm{R}$ who have immunity protecting them from future infection - perhaps it can be assumed that all have it - and the actual degree of physical distancing, which ultimately depends more on individual inclinations than behavioural regulations) the restrictions can be lifted, especially those that have so grievously affected the functioning of the economy.

Table 1. Anti-Covid vaccines currently authorized in the UK.

\begin{tabular}{|c|c|c|c|}
\hline Name(s) & Type & Manufacturer(s) & Date approved \\
\hline BNT162 $^{c}$ & mRNA & Pfizer & 2 December $2020^{a}$ \\
\hline mRNA-1273 ${ }^{d}$ & mRNA & Moderna TX Inc. & 18 December $2020^{b}$ \\
\hline AZD1222 (ChAdOx1) ${ }^{e}$ & $\begin{array}{l}\text { Nonreplicating viral } \\
\text { vector (recombinant) }\end{array}$ & $\begin{array}{l}\text { AstraZeneca } \\
\text { (Medlmmune UK Ltd) }\end{array}$ & 30 December $2020^{a}$ \\
\hline
\end{tabular}

a Authorization for temporary supply granted by the UK Department of Health and Social Care (DHSC) and the Medicines and Healthcare Products Regulatory Agency (MHRA). No marketing authorization.

$b$ Emergency use authorization (EUA) granted by the US Food and Drug Administration (FDA).

$c$ US patent application 2020/0155671 (Sahin et al., 21 May 2020) "PARTICLES COMPRISING A SHELL WITH RNA" (mRNAdecorated liposomes).

$d$ US patent 10,702,600 (Ciaramella et al., 7 July 2020) "BETACORONAVIRUS MRNA VACCINE".

$e$ US patent 9,714,435 (Dicks et al., 25 July 2017) "SIMIAN ADENOVIRUS AND HYBRID ADENOVIRAL VECTORS".

This new state of affairs has initiated a vigorous debate about the merits of vaccination, because clearly its efficacy for the population as a whole (as distinct from individual efficacy) depends on a high uptake. This is a general principle of public health. Many vaccines are offered to infants (Table 2) and uptake is high enough to ensure that any outbreaks of the diseases vaccinated against are sporadic and localized. This policy enjoys wide general acceptance. Not only does it largely prevent the possibly debilitating occurrence of these diseases among adults, but also the cost of vaccinating infants is far less than the cost of having to treat the disease, which might be quite prevalent among an unvaccinated population. Hence, simple considerations of economy provide sufficient justification for vaccination [3]. It is, of course, assumed that the vaccines cause no deleterious sideeffects, and there seems to be no convincing evidence to the contrary. ${ }^{1}$ Regarding Covid, the economic argument is immeasurably amplified because the enforced lockdown has resulted in a decline of economic activity and, hence, prosperity (as measured, for example by gross domestic product, GDP) so great as to possibly cause more deaths through impoverishment (since life expectancy is well correlated with GDP) than would otherwise have happened from contracting Covid [5].

The higher the vaccine uptake, the more quickly physical ("social") distancing restrictions can be relaxed. The UK economy has been especially badly affected by them because of its predominance of service industries, many of which depend on bringing people together (e.g., dining out, spectator sports, other entertainment), rather than manufacturing. In order to promote high uptake, there have even been calls for compulsory vaccination. Citizens have accepted compulsory wearing of face

\footnotetext{
1 Such evidence was purportedly gathered for a mumps-measles-rubella vaccine by A. Wakefield, but subsequently found to have been fabricated, apparently with the motivation of discrediting a rival vaccine for commercial reasons [4]. 
Table 2. UK immunization schedule for infants.

\begin{tabular}{lll}
\hline Disease & Date introduced & ${\text { Coverage }(\%)^{a}}^{a}$ \\
\hline 6-in-1 & $2000(\mathrm{EU})$ & 93 \\
Hib/MenC & 2006 & 90 \\
MenB & 2015 & 96 \\
MMR & 1988 & 94 \\
PCV & 2006 & 94 \\
Rotavirus & 2013 & 93 \\
\hline
\end{tabular}

a Approximate figures (for first dose) - they vary by year and region.

masks and other restrictions on social gathering, subordinating individual freedom to the greater good of the state [6]. Nevertheless, a medical intervention is something different. As we know, the regulatory requirements for any product that enters the human body are far stricter than for products that remain outside, or solely in the gastrointestinal tract. Compulsory vaccination for all citizens would constitute mass medication, which is generally considered to violate human rights and be unconstitutional, ${ }^{2}$ as are eugenic interventions. Besides, there is no real scientific or medical justification for it. Even in the absence of any restrictions on social interaction, $90 \%$ take-up is likely to be more than adequate to achieve population immunity. Of course, it should be borne in mind that the presently available vaccines are only approved for adults, whereas children (under 16) make up almost $20 \%$ of the population. As yet, little is known about the role of children in the dynamics of Covid-19. It appears that they are less susceptible to contracting the disease and likely to be asymptomatic if they do. Nevertheless, they may still play a rôle in transmission and, therefore, should be included in considerations of population immunity. Hence, it is reasonable to encourage a high take-up among the adult population, also bearing in mind that valid medical reasons (e.g., allergies to the ingredients) will doubtless prevent some people from being vaccinated, and that none of the vaccines are $100 \%$ effective.

\section{The vaccines}

Avoiding the dangerous ground of compulsory vaccination allows it to be delivered with the consent of the recipient. Indeed, recipients must confirm their consent with their signatures. Can this really be called informed consent? The "Regulation 174" information for UK recipients of the vaccine comprises four pages of text, including the names of the ingredients but not their actual quantities. Proper appraisal of the risks versus benefits is a fairly onerous task that would require several hours at least even for a scientist with extensive domain knowledge. For laypersons such an appraisal is likely to be impracticable. Hence, they must "trust the experts". Is this reasonable? Without wishing to impugn the integrity of any individual expert, it must be said that the track record of government expertise ostensibly acting for the benefit of citizens is dismal. It is especially prominent in the modern built environment, as evinced (were any evidence required beyond what can be seen with one's own eyes simply by walking around) by the seemingly endless reports on beautifying our surroundings that have been issued in recent years. Regulatory agencies such as the European Food Safety Agency (EFSA) appear to be riddled with conflicts of interest [8], hence their rulings must be considered to be generally unreliable. Objective assessment of safety measures introduced to combat leakages of radioactive waste, bovine spongiform encephalopathy (BSE) \&c. have shown them to be wildly off the mark, sometimes costing hundreds of times more than could possibly be justified by the benefits [9]. Only the National Institute for Clinical Excellence (NICE, now called the National Institute for Health and Care Excellence) has been shown to be reasonable in its judgments, albeit a little too conservative [9]. Otherwise there seems to be a general tendency to overreact to perceived dangers. This is by no means limited to the UK-it has been shown that the authorities' responses to the Chernobyl and Fukushima nuclear disasters were wildly disproportionate and probably ended up doing more harm than good [10]. Some would say the same about the widely enforced Covid lockdowns. Given this history, it is not surprising that there seems to be no attempt to encourage a sober, individual assessment of anti-Covid vaccination risk/ benefit, possibly using readily understandable concepts such as temporary age burden (TAB) [11]. Altogether the vaccination campaign has been much too shrill, with endless pictures in the media of people being vaccinated alongside "celebrities" mostly lacking medical expertise affirming their support. It might be said that this approach is necessary for a largely ignorant population. If so, that is a terrible indictment of education policy and its practical realization during the last 75 years, and suggests a state of affairs not dissimilar to that prevailing, say, in France in the early 18th century. Nor is there much evidence of critical appraisal of the course of the disease among our legislators. Spencer wrote in 1851 that "the legislator who is wholly or in great part uninformed concerning the masses of facts which he must examine before his opinion on a proposed law can be of any value, and who nevertheless helps to pass that law, can no more

${ }^{2} \mathrm{Cf}$. the case of mass fluoridation of piped domestic drinking water [7]. 
be absolved if misery and mortality result, than the journeyman druggist can be absolved when death is caused by the medicine he ignorantly prescribes" $[12] .{ }^{3} \mathrm{~A}$ noted expert on vaccination has written a review praising it with almost religious fervour: it is probably "the only medical intervention that is recommended for every single individual on the planet", and those who question "one of the most transformative interventions for survival and health" are firmly placed beyond the pale [14]. The confounding effects of the general increase in prosperity and sanitation on mortality are overlooked, as is a feature of adult vaccination that is particularly relevant to the anti-Covid campaign, namely the effect of "moral hazard", which may lead to careless behaviour among those who have been vaccinated. A more subtle effect is that vaccination will tend to promote phylogenetic maladjustment [15]. Its consequences at the very large (global!) scale of vaccination propounded by Piot et al. [14] have not, I think, being investigated.

Although vaccination is generally considered to have begun with Edward Jenner's successful vaccination against smallpox in 1796, its principle is rooted in Paracelsus' (1493-1541) idea of similia similibus curantur, ${ }^{\mathbf{5}, \mathbf{6}}$ with which he greatly expanded medical theory, hitherto rooted in Hippocrates' contraria contrariis curantur, allopathic medicine, well exemplified by antibiotics. But in a sense, the preëmptive, prophylactic application of vaccines makes them rather exemplars of similia similibus conservantur. ${ }^{7}$

Now, it may well be that anti-Covid vaccination is worthwhile, as recent assessments of the route out of lockdown seem to suggest [11], but the campaign to promote vaccination is not helped by the general impression of a fog of disinformation alongside fervent exhortations from people who do not have any special knowledge about the matter, instead of setting out the calculations demonstrating the benefits with lapidary clarity. ${ }^{8}$ Such a fog inevitably raises suspicions among anyone minded to assess the matter critically.

Appeals to "public spiritedness", "unselfishness" and the like in order to encourage a high uptake of the vaccine may even be counterproductive. Such appeals inevitably lead to scrutiny of all aspects of public life. An extraordinary liberality in awarding large gratuities to senior officials leaving a public sector rôle - in which they may have anyway enjoyed a salary disproportionately large in relation to their duties - seems to have become permanently embedded in our culture. There seem to be few, if any, contemporary examples of officials unselfishly declining exit payments. Doubtless many other conspicuous examples of a selfish lack of public spiritedness can be found. They abound in property development, in which large, ugly residential and other schemes are forced through despite vehement local opposition. Appealing to unselfishness becomes rather incongruous when so many examples of selfish abuses exist. The incongruity is all the more apparent because, on the face of it, the benefits of vaccination to both individual and society should be readily perceived without the need for overweening exhortation.

\section{Individual risk}

The invasive nature of a medication like a vaccine makes it important to examine the risks and benefits. Risk is the product of exposure and hazard, and this maps onto

$$
\mathbf{P}\{\text { disease }\}=\mathbf{P}\{\text { infection }\} \times \text { susceptibility }
$$

where $\mathbf{P}\{X\}$ denotes the probability of $X$. $\mathbf{P}$ \{infection $\}$ is perhaps a relatively simple function of proximity, duration and frequency of contacts with already-infected personsas with flu and the common cold. Susceptibility depends on genetic, immune, metabolic and behavioural parameters. It should be possible to estimate it if one knows a person's genome, epigenome, immune status, nutritional status (including vitamins and trace minerals) and morbidity. Age - counted by the number of times Earth has orbited the sun-is a surrogate for some of these features, albeit a rather crude one. The goal is for an individual to form a somewhat objective impression of health, a kind of order parameter of health, analogous to the magnetization of a ferromagnetic in a heat bath. $\mathbf{P}\{$ infection $\}$ also depends on behavioural attitudes, which

\footnotetext{
3 Spencer seems to have been no enthusiast of vaccination. He was concerned about the possibility of the propagation of subdued forms of constitutional disease through the agency of vaccination [13].

4 This uncritical panegyric admittedly appeared in a periodical that is, strictly speaking, a magazine rather than a scientific journal. Nevertheless, it is held in very high regard within the scientific community, many of whom strive very hard to place reports of their scientific work in its pages.

5 This principle in turn has an affinity with Paracelsus' well-known maxim "the poison is in the dose". At high dose, the infectious agent cause disease, whereas an attenuated dose merely stimulates the immune system and prevents the disease.

6 See further discussion by Waisse [16].

7 By putting the verb in the subjunctive to form similia similibus curentur, Samuel Hahnemann (1755-1843) later founded another distinct strand of medicine, homeopathy.

8 It might be argued that the successfully concluded clinical trials of the vaccines give confidence in their safety and efficacy. If, however, the thesis of Goldacre in his book Bad Pharma is correct, one should be cautious in giving credence to the reported trial results [17].
} 
may strongly influence the pattern of contacts experienced by a person. Some people have relished lockdown, enjoying the blue skies, cleaner air, freedom from the scourge of road traffic and so forth and adapting well to the paucity of human contacts. Others long for the return of the opportunity to mingle with large crowds at mass sporting events, festivals \&c. Clearly $\mathbf{P}\{$ infection $\}$ is very different for different people.

Vaccination essentially reduces susceptibility to almost zero. On the other hand, as invasive medication it is not itself free from risk and this risk needs to be weighed against the risk from contracting the disease while unvaccinated. It should be noted (Table 1) that two of the currently approved vaccines are of the pioneering mRNA type that has not previously been introduced. Risks of possible side effects - possibly many months or a year in the future-incontrovertibly exist and should be weighed against the benefits for each individual, whose exposure and susceptibility to Covid may be different from those of others. For someone immersed an intense work régime, even a single day of debility while recovering from the immediate side effects of the vaccine may exceed the consequences of contracting Covid unvaccinated. These risks can and should be quantified on an individual basis.

\section{Vaccine passports}

A vaccinated person usually receives a certificate, a little card, giving details of dose and date \&c.; the proposed "passport" is merely a more sophisticated version of the card that is machine-readable and possibly wholly electronic and conforming to an international standard. While it has been proposed for domestic use, it is as an instrument for facilitating international travel that it may find its greatest utility.

Domestic use-i.e., making it mandatory for entering bars, restaurants, theatres, sporting events \&c.- - does not seem to have been properly thought through. Vaccination primarily protects the individual. It is up to the individual whether he wishes to expose himself to the risk of possible infection. As mentioned, it is not yet known whether vaccination prevents transmission. If it does not, then of course a "passport" is pointless. If vaccination does prevent, then indeed the mandatory passport will reassure other guests that no one present is likely to transmit the virus, but since they are themselves vaccinated they should not need such reassurance. People who wish to visit such venues should themselves know that they should not do so unless they have been vaccinated - for their own protection. Someone who is suffering from the disease should anyway know that he should not mix with other people until he has recovered. A difficulty is that a substantial proportion of carriers of SARS-CoV-2 are asymptomatic. But the passport cannot guarantee that its holder is not a carrier. Conceivably, a passport requirement could serve to limit the liability of the owner of the venue with respect to any guest who becomes infected, but that would not change the onus of individual responsibility. Were passports to be introduced, it would make little sense not to make them mandatory for entering shops and using public transport. Presumably people without a passport would simply have to buy essential foodstuffs in open markets. ${ }^{9}$

The case for a mandatory vaccination passport for international travel is stronger, but again only if vaccination prevents transmission. As long as an unvaccinated foreigner who falls ill has to meet all expenses associated with treatment and recovery, which is anyway often the case, it should be a matter of individual responsibility. ${ }^{10}$ On the other hand if vaccination does prevent transmission, then clearly there is a very strong case for requiring a passport: obviously a country wishes to protect its citizens. The problems of implementation - validation \&c. - would be similar to those for ordinary passports. It has been proposed that they might be implemented on so-called "smart" cellphones. Presumably there would have to be a paper version for those not possessing cellphones. Were such a "passport" to be introduced, it would seem strange to restrict it to Covid-19. Influenza would be an obvious candidate for inclusion; since we are now more aware of the likelihood of future epidemics, setting up the vaccination passport system would be useful for dealing with them.

In fact, public health has not kept up with the exponential growth of passenger aviation during the last few decades. The enormous number of people traveling from one country to another has greatly favoured the spreading of infections: the network of air services has transformed our world into a "small world" [18]. There is a slow growth of cognizance of its implications for public health [19-22]. Presumably very powerful commercial interests have hitherto prevented the introduction of even minimal restrictions on the use of passenger air services. Little seems to have been learned from the past. It is recognized that the mass transport (in ships) of demobilized soldiers after World War I greatly contributed to the spread of so-called "Spanish" influenza

\footnotetext{
9 Here in might be argued that people were obliged to have ration cards to purchase necessities during and after World War II, but the difference is that possessing a ration card was not associated with a medically invasive intervention.

${ }^{10}$ An unvaccinated foreigner might catch the disease from an infected native, and then go on to infect other natives. This strengthens the case for a mandatory passport even if vaccination does not prevent transmission.
} 
[23]. On the other hand, finding a compromise may be difficult. The aviation industry has enormously contributed to economic growth, which has increased prosperity, which extends life expectancy [24].

Vaccine passports might seem to be a perfect way to reconcile the containment or infectious diseases and commercial prosperity, but of course viruses do not idly rest while vaccines are developed and disseminated. New variants of pathogenic viruses like influenza and the SARS coronaviruses arise all the time; host immunity through vaccination can, as an obvious consequence of the tenets of Darwinian selection, exacerbate selection for virulence [25]. A further possible effect is that, by preventing death, vaccination actually increases transmission [26]. ${ }^{11}$

One should not lose sight of the fact that the desirable endpoint is not vaccination per se but immunity, which can also be acquired by having recovered from the disease. ${ }^{12}$ It seems unfair to exclude from international travel those who do not happen to have been vaccinated but are as immune as someone who has been. Hence, any meaningful passport needs to certify immunity. The prevalence of antibodies to the virus seems to be a good indicator of that. We do not yet know how long immunity, whether from having contracted the disease or from having been vaccinated, lasts, but there are reasonably effective ways of testing for the presence of antibodies in the bloodstream. This is what should be certified by the passport.

Such certification would necessarily be less discriminatory than a vaccination passport. It would simply certify an objective fact, the one that seems to be most relevant for combating Covid. There may be good reasons why some adults do not get vaccinated. They may not have been offered the vaccine (the younger cohorts); they may have an allergy to one of the ingredients; they may have already contracted Covid; or their risk from vaccination is greater than their risk from remaining unvaccinated. Unless their (voluntary) choice of occupation or leisure activities brings them into contact with many people, they should not be pressured into accepting vaccination.

\section{Conclusions}

The development of anti-Covid vaccines is a welcome achievement, above all for anyone who is obliged to come into contact with many people. This applies to a great number of public-facing rôles, including policemen, teachers, shopkeepers, janitors, ushers, taxi drivers, bus conductors, railway ticket inspectors and restaurateurs, but above all frontline health service workers, who are inevitably more likely to be exposed to infectious agents, and who are already obliged to be vaccinated against certain diseases such as hepatitis B.

Given the considerable uncertainties around Covid, it is understandable that governments are striving to ensure that all adults receive the vaccine. It does not look as though there are going to be control experiments, hence the impact of vaccination will have to be assessed from models [11]. The key attributes over which one has some control for ensuring population immunity and hence guaranteeing that the disease dies out are individual immunity and number of contacts. Individual immunity is acquired by having had the disease as well as by vaccination, hence plans to vaccinate "all" the adult population (anyway only about $80 \%$ of the total population) are somewhat wasteful and unnecessary. Furthermore, the virus itself is coëvolving alongside human society and the possibility of the promotion of new, more virulent strains by vaccination should not be overlooked. A corollary is that it will be sensible to maintain some degree of physical ("social") distancing.

It also seems sensible to require some form of certification of immunity (rather than vaccination as such) for international travelers. The drawback, apart from the immense administrative burden, is its inevitable arbitrariness. Could one travel freely throughout immense realms such as Russia, China, the USA and Canada, but be stopped within walking distance of one's home in San Marino or Andorra? Equitable certification demands that it is required for moving out of one's local area, possibly defined as city, county or state in federal or confederal jurisdictions.

The enormous cost of such measures should not in itself be seen as a hindrance. The worry at present is rampant growth of unemployment, which could easily be soaked up by the labour-intensive implementation of such a scheme of certified travel. Although in our present age electronic certification is highly alluring, it should not be forgotten that electronic documents can be subjected to tampering without leaving traces far more readily than paper ones [27].

Ultimately, in the case of vaccination against smallpox, it became a global aim to eradicate the disease completely. This seems less likely to be able to happen in

\footnotetext{
${ }^{11}$ A counterexample is Ebola virus. Mortality is so great that outbreaks quickly die out. Hence Ebola virus does not constitute a serious public health threat. On the other hand, vaccinating against it, as espoused by Piot [14], might turn it into one.

${ }^{12}$ Some people might be immune even if they had never caught Covid, simply through their history of exposure to other pathogens and the intrinsic randomness of the immune system.
} 
the case of Covid, not least because of the relative lability of the virus genome, as with influenza. Nevertheless, regardless of the ultimate outcome of vaccination it seems clear that the challenges of finding, testing, approving and manufacturing at scale the vaccine, and then distributing, storing (in some cases at temperatures as low as $-80^{\circ} \mathrm{C}$ ) and administering it to the vast majority of the adult population, all with the utmost urgency, is giving a great boost to many disparate components of the economy in a manner not unrelated to Hirschman's notion of "maintenance compulsion" [28].

\section{J.J. RAMSDEN}

\section{References}

1. J.J. Ramsden, COVID-19. Nanotechnol. Perceptions 16 (2020) 5-15.

2. J.J. Ramsden, On the immunization criterion for Covid-19. Nanotechnol. Perceptions 16 (2020) 228-229.

3. P.A. Muennig and K. Khan, Cost-effectiveness of vaccination versus treatment of influenza in healthy adolescents and adults. Clin. Infectious Diseases 33 (2001) 8179-1885.

4. T.S.S. Rao and C. Andrade, The MMR vaccine and autism: Sensation, reputation, retraction, and fraud. Indian $J$. Psychiatry 53 (2011) 95-96.

5. P. Thomas, J-value assessment of how best to combat COVID-19. Nanotechnol. Perceptions 16 (2020) 16-40.

6. J.J. Ramsden, China: a modern Machiavellian state. J. Biol. Phys. Chem. 20 (2020) 47-49.

7. D. Cross, An unhealthy obsession with fluoride. Nanotechnol. Perceptions 11 (2015) 169-185.

8. C. Robinson, N. Holland, D. Leloup and H. Muilerman, Conflicts of interest at the European Food Safety Authority erode public confidence. J. Epidemiol. Community Health 67 (2013) 717-720.

9. P.J. Thomas, D.W. Stupples and M.A. Alghaffar, The extent of regulatory consensus on health and safety expenditure. Part 2. Applying the J-value technique to case studies across industries. Trans. IChemE B 84 (2006) 337-343.

10. P. Thomas, Responding after a big nuclear accident. Nanotechnol. Perceptions 16 (2020) 267-330.
11. P. Thomas, Measuring and controlling the Covid-19 epidemic. Nanotechnol. Perceptions 14 (2018) 69-79.

12. H. Spencer, The Man versus the State, p.120. Caldwell, Idaho: Caxton Printers (1960) (originally published in 1884).

13. H. Spencer, Education, footnote on p. 210. London: Williams \& Norgate (1911) (written in 1878).

14. P. Piot et al., Immunization: vital progress, unfinished agenda. Nature 575 (2019) 119-129.

15. S. Boyden, Evolution and health. Ecologist 3 (1973) 304-309.

16. S. Waisse, Contraria contrariis curantur, Similia similibus conservantur: Como utilizar a matéria médica no século XVIII? Circumscribere 14 (2014) 6-72.

17. J.J. Ramsden, Review of B. Goldacre, Bad Pharma. London: Fourth Estate (2012). J. Biol. Phys. Chem. 20 (2020) 147-151.

18. M. Boots and A. Sasaki, 'Small worlds' and the evolution of virulence: infection occurs locally and at a distance. Proc. R. Soc. B 266 (1999) 1933-1938.

19. A.T. Pavia, Germs on a plane: Aircraft, international travel, and the global spread of disease. J. Infectious Diseases 195 (2007) 621-622.

20. L. Budd, M. Bell and T. Brown, Of planes, planes and politics: Controlling the global spread of infectious diseases by air. Political Geography 28 (2009) 426-435.

21. A. Mangili, T. Vindenes and M. Gendreau, Infectious risks of air travel. Microbiol. Spectrum 3 (2015) IOL5-0009-2015.

22. A. Findlater and I.I. Bogoch, Human mobility and the global spread of infectious diseases: a focus on air travel. Trends Parasitol. 34 (2018) 772-783.

23. G. Swinden, The Navy and the 1918-19 influenza pandemic. J. Mil. Veterans Health 28 (2020) 7-10.

24. P. Thomas, Does health spending need to outpace GDP per head? Nanotechnol. Perceptions 13 (2017) 17-30.

25. M.J. Mckinnon, S. Gandon and A.F. Read, Virulence evolution in response to vaccination: The case of malaria. Vaccine 26 (suppl. 3) (2008) C42-C52

26. A.F. Read et al., Imperfect vaccination can enhance the transmission of highly virulent pathogens. PLOS Biol. 13 (2015) e1002198.

27. W. Wirth, The end of the scientific manuscript? J. Biol. Phys. Chem. 2 (2002) 67-71.

28. A.O. Hirschman, The Strategy of Economic Development. New Haven: Yale University Press (1958). 